\title{
TRAIL in Combination with Subtoxic 5-FU Effectively Inhibit Cell Proliferation and Induce Apoptosis in Cholangiocarcinoma Cells
}

\author{
Ruethairat Sriraksa, Temduang Limpaiboon*
}

\begin{abstract}
In the past decade, the incidence and mortality rates of cholangiocarcinoma (CCA) have been increasing worldwide. The relatively low responsiveness of CCA to conventional chemotherapy leads to poor overall survival. Recently, tumor necrosis factor-related apoptosis-inducing ligand (TRAIL or Apo2L) has emerged as the most promising anti-cancer therapeutic agent since it is able to selectively induce apoptosis of tumor cells but not normal cells. In this study, we aimed to investigate the therapeutic effect of TRAIL in CCA cell lines (M213, M214 and KKU100) compared with the immortal biliary cell line, MMNK1, either alone or in combination with a subtoxic dose of 5-fluorouracil (5-FU). We found that recombinant human TRAIL (rhTRAIL) was a potential agent which significantly inhibited cell proliferation and mediated caspase activities (caspases 8,9 and 3/7) and apoptosis of CCA cells. The combined treatment of rhTRAIL and 5-FU effectively enhanced inhibition of CCA cell growth with a smaller effect on MMNK1. Our finding suggests TRAIL to be a novel anti-cancer therapeutic agent and advantage of its combination with a conventional chemotherapeutic drug for effective treatment of CCA.
\end{abstract}

Keywords: Novel cancer therapy - TRAIL/Apo2L - non-conventional anti-cancer therapy - apoptosis

Asian Pac J Cancer Prev, 16 (16), 6991-6996

\section{Introduction}

Cholangiocarcinoma (CCA) is a malignancy of bile duct epithelium cell lining accounting for $10-20 \%$ of primary liver cancers (Shaib and El-Serag, 2004). The incidence and mortality of the disease, in particular intrahepatic cholangiocarcinoma (ICC), have been increasing worldwide (Patel et al., 2001; Taylor-Robinson et al., 2001; Shaib et al., 2004). The study focused in East and South-Eastern Asia has indicated that age-adjusted incidence rate of ICC varied by region in which the highest incidence has been reported in Khon Kaen, Thailand with $90 \%$ of liver cancer patients are CCA cases (Shin et al., 2010). Surgical resection is only a potentially curative approach for the CCA patients. Unfortunately, a vast majority of the CCA cases are unresectable and commonly presented in the advanced stages at an initial diagnosis (Mosconi et al., 2009; Morise et al., 2010). For other treatment modalities, chemotherapy and radiotherapy have been used as the adjuvant therapy for this fatal cancer. Bhudhisawasdi et al. (2012) showed that CCA patients who received complete postoperative adjuvant chemotherapy significantly improved overall survival compared to those who had incomplete or no postoperative adjuvant treatment. The widely used chemotherapeutic agents for CCA include 5-fluorouracil (5-FU), gemcitabine and cisplatin, either alone or in combination (Khan et al., 2002; Thongprasert, 2005; Mosconi et al., 2009; Morise et al., 2010). However, previous clinical studies have reported the relatively low responsiveness of CCA to chemotherapy with a partial response approximately 1020\% (Patt et al., 2001; Martin and Jarnagin, 2003; Lee et al., 2004; Khan et al., 2005). In term of the most often used 5-FU-based regimens (single and combined uses), the response rates are up to $40 \%$ and median survival is less than 15 months (Thongprasert, 2005; Morise et al., 2010). Therefore, new agents and innovative modalities are seriously required for effective outcome of CCA patients.

Tumor necrosis factor-related apoptosis-inducing ligand or Apo2 ligand (TRAIL or Apo2L) is a member of the tumor necrosis factor (TNF) gene superfamily that induces apoptosis through engagement of death receptors. TRAIL interacts and forms homotrimers with its cognate death receptors, DR4 (TRAILR1) and DR5 (TRAILR2), which contain a conserved death domain motif. In addition, TRAIL can bind to the decoy receptors, DcR1 (TRAILR3) and DcR2 (TRAILR4), which have the extracellular domains that are homologous to DR4 and DR5. However, DcR1 lacks of the death domain while DcR2 contains a truncated and non-functional death

Centre for Research and Development of Medical Diagnostic Laboratories, Faculty of Associated Medical Sciences, and Liver Fluke and Cholangiocarcinoma Research Center, Faculty of Medicine, Khon Kaen University, Khon Kaen, Thailand *For correspondence: temduang@kku.ac.th 
domain resulting in no apoptotic signal transduction. TRAIL can also bind to a soluble receptor, osteoprotegerin (OPG) at a low affinity (Huang and Sheikh, 2007; Kruyt, 2008). Importantly, many studies have demonstrated that TRAIL selectively induces apoptosis in tumor cells both in vitro (Pitti et al., 1996; Wiley et al., 1995) and in vivo (Ashkenazi et al., 1999; Walczak et al., 1999) with no adverse effect on normal cells indicating TRAIL as a promising agent for cancer therapy. We have recently shown that death receptor-induced apoptosis through TRAIL signaling is rarely silenced by epigenetic aberration in term of DNA methylation (Sriraksa et al., 2011) suggesting the advantage for an alternative cancer therapy using recombinant TRAIL or TRAIL receptor agonistic monoclonal antibodies to induce cell death in CCA. In other words, it is worth to therapeutically induce apoptosis via TRAIL signaling cascade as it selectively kills cancer but not normal cells (Kim et al., 2000; Kruyt, 2008; Mahmood and Shukla, 2010). In the present study, we investigated the therapeutic effect of recombinant human TRAIL (rhTRAIL) in CCA cell lines (M213, M214 and KKU100) in comparison with the immortal biliary cell line, MMNK1, either alone or in combination with 5-FU at a subtoxic dose.

\section{Materials and Methods}

\section{Cell lines, cell culture and agents}

A panel of human CCA cell lines (M213, M214 and KKU100) and an immortal biliary cell line (MMNK1) were used in this study. All CCA cell lines were established in the Liver fluke and Cholangiocarcinoma Research Center, Faculty of Medicine, Khon Kaen University (Khon Kaen, Thailand). Cell lines were cultured in Dulbecco's Modified Eagle Medium (DMEM; Gibco-BRL, Ontario, Canada) supplemented with $10 \%$ fetal bovine serum, 100 $\mathrm{U} / \mathrm{mL}$ penicillin and $100 \mu \mathrm{g} / \mathrm{ml}$ streptomycin (Gibco/ Invitrogen, Grand Island, NY), and incubated at $37^{\circ} \mathrm{C}$ with humidified atmosphere of $5 \% \mathrm{CO}_{2}$.

5-FU was purchased from Pharmachemie BV (Haarlem, Netherlands) and freshly prepared by diluting with culture medium to reach the optimal concentration before use. Recombinant human TRAIL (rhTRAIL) was purchased from R\&D Systems (Minneapolis, MN) and prepared as a stock solution $(100 \mu \mathrm{g} / \mathrm{ml})$ in sterile PBS with $0.1 \%$ bovine serum albumin and stored at $-70^{\circ} \mathrm{C}$ until use.

$R N A$ isolation and semi-quantitative reverse transcriptionpolymerase chain reaction ( $R T-P C R)$

RNA was extracted from all cell lines using SV Total RNA Isolation System (Promega Corporation, Madison, WI). For cDNA synthesis, $1 \mu \mathrm{g}$ of total RNA was reverse transcribed in $20 \mu \mathrm{L}$ of PCR reaction using ImProm-II ${ }^{\mathrm{TM}}$ Reverse Transcription System (Promega) following the manufacturer's protocols. Specific primers for mRNA expression profile of human TRAIL signaling related genes and p53 were designed from sequences available in the Genbank database using Primer-BLAST (http://www. ncbi.nlm.nih.gov/tools/primer-blast/) as detailed in Table 1. The housekeeping gene, glyceraldehyde 3-phosphate dehydrogenase (GAPDH) was used as an endogenous control to normalize the amount of TRAIL signaling related transcripts in each reaction. A total volume of 25 $\mu \mathrm{L}$ PCR reaction was carried out using a G-Storm GS482 thermo cycler (GRI). PCR products were then separated on a $2 \%$ agarose gel, stained with ethidium bromide and visualized under UV illumination.

\section{Cell proliferation assay}

Sulforhodamine B (SRB) assay was carried out to determine cell proliferation as described previously (Vichai and Kirtikara, 2006). In brief, $100 \mu \mathrm{L}$ of cell lines with density $1 \times 10^{4}$ were seeded in triplicate in a flatbottom 96-well plate and allowed to adhere for $24 \mathrm{~h}$. Then, $100 \mu \mathrm{L}$ of medium containing different concentrations of selection agent were added to each well. Cells were treated with various final concentrations of rhTRAIL as follows; 10, 25, 50, 100, 250 and $500 \mathrm{ng} / \mathrm{ml}$ or without as an untreated control. After incubation for $72 \mathrm{~h}$, cell monolayer was fixed with $10 \%(\mathrm{~W} / \mathrm{V})$ trichloroacetic acid and stained with SRB for $30 \mathrm{~min}$, after which the excess dye was then removed by washing repeatedly with $1 \%$ (V/V) acetic acid. The protein-bound dye was dissolved in $10 \mathrm{mM}$ Tris base solution for absorbance determination at $510 \mathrm{~nm}$ using a microplate reader (Tecan Ltd., Reading, UK). The percentage of cell proliferation was calculated ([mean $\mathrm{OD}_{\text {sample }}$-mean $\mathrm{OD}_{\text {day0 }} /$ mean $\mathrm{OD}_{\text {negative control }}$-mean $\left.\left.\mathrm{OD}_{\text {day0 }}\right] \times 100\right)$ and represented as mean \pm standard deviation (SD) of at least three independent experiments. The $\mathrm{IC}_{50}$ and $\mathrm{IC}_{20}$ (a subtoxic dose) were then determined for each agent and cell line.

According to our previous study, a subtoxic concentration $\left(\mathrm{IC}_{20}\right)$ of 5-FU against cholangiocyte MMNK1 at $8 \mu \mathrm{M}$ (Sriraksa and Limpaiboon, 2013) was used for the study of combined treatments with rhTRAIL.

\section{Apoptosis study by caspase 8,9 and 3/7 activities}

Apoptosis was determined using Caspase-Glo ${ }^{\circledR} 8$, Caspase-Glo $^{\circledR} 9$ or Caspase-Glo ${ }^{\circledR}$ 3/7 Assays (Promega) as directed by the manufacturer's instructions. Briefly, 50 $\mu \mathrm{L}$ of cells with density $1 \times 10^{4}$ were seeded in triplicate in a flat-bottom 96 -well plate, incubated at $37^{\circ} \mathrm{C}$ for $24 \mathrm{~h}$ to allow cell adherence, and treated with 5-FU alone $(8 \mu \mathrm{M})$, TRAIL alone (10 ng/ml) or combined treatment for $48 \mathrm{~h}$. Culture medium was represented as an untreated control. After $48 \mathrm{~h}$, the plates were removed from the incubator and allowed to equilibrate to room temperature for 30 min. Then, $50 \mu \mathrm{L}$ of Caspase-Glo ${ }^{\circledR} 8$, Caspase-Glo ${ }^{\circledR} 9$ or Caspase-Glo ${ }^{\circledR}$ 3/7 reagents were added to each well and incubated at room temperature for $1 \mathrm{~h}$. The luminescent signal was measured using the SpectraMax ${ }^{\circledR}$ L Microplate Luminometer (Molecular Devices, Sunnyvale, CA). The activity of caspase was determined and represented as a relative light unit (RLU). The experiments were performed in triplicate and repeated three times.

\section{Statistical analysis}

The statistical analysis was performed using SPSS software (SPSS version 16.0, Chicago, IL). The difference of cell proliferation or caspase 8,9 and $3 / 7$ activities in each experimental condition was analyzed by using 
TRAIL with Subtoxic 5-FU Effectively Inhibits Cell Proliferation and Induces Apoptosis in Cholangiocarcinoma Cells

Student's t-test. Two-sided $\mathrm{P} \leq 0.01$ was considered statistically significant.

\section{Results}

Recombinant human TRAIL inhibits proliferation of CCA but not an immortal cholangiocyte

The rhTRAIL inhibited cell proliferation with high and moderate effectiveness in KKU100 and M214, respectively, but had no effect on M213 and the immortal cholangiocyte (MMNK1) (Figure 1). According to our finding, we selected the concentrations of rhTRAIL at 10 and $100 \mathrm{ng} / \mathrm{ml}$ as low-cytotoxic doses to immortal biliary cell, MMNK1 for the further study.

Combined treatment of subtoxic dose 5-FU and lowcytotoxic dose of rhTRAIL can inhibit cell growth in CCA but does not affect expression of TRAIL related genes and $p 53$

We investigated the effect of a subtoxic dose of 5-FU $(8 \mu \mathrm{M})$ in combination with rhTRAIL $(10$ or $100 \mathrm{ng} / \mathrm{ml})$ on cell proliferation of M213, KKU100 and MMNK1. We found that neither 5-FU nor rhTRAIL (10 or $100 \mathrm{ng}$ / $\mathrm{ml}$ ) significantly decreased proliferation of MMNK1 but the combination of both agents was able to inhibit cell proliferation, however, the proliferation of MMNK1 was more than $60 \%$ (Figure 2A). M213 was more sensitive to 5 -FU than to 10 or $100 \mathrm{ng} / \mathrm{ml}$ rhTRAIL. However, the combined treatment of 5-FU $(8 \mu \mathrm{M})$ and 10 or $100 \mathrm{ng} /$ $\mathrm{ml}$ rhTRAIL significantly enhanced inhibition of M213 growth when compared to untreated, 5-FU, $10 \mathrm{ng} / \mathrm{ml}$

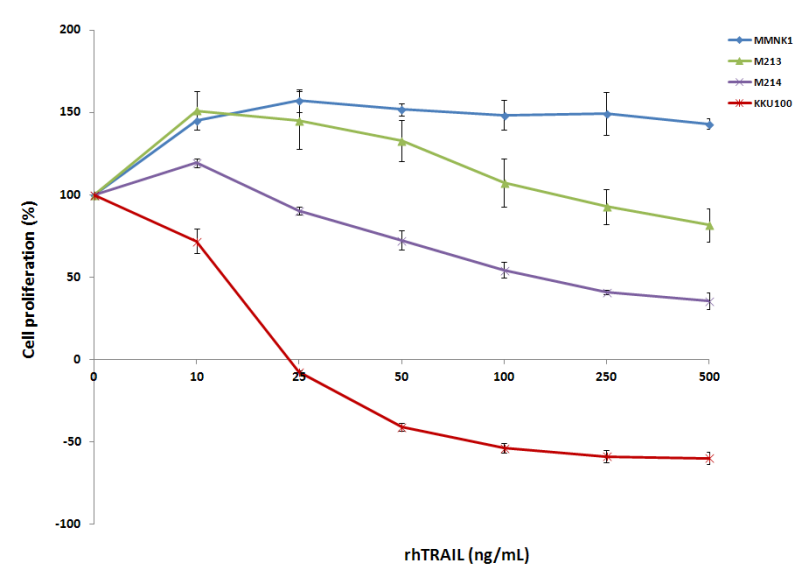

Figure 1. The Effect of rhTRAIL on Cell Proliferation in a Spectrum of Human CCA Cell Lines and Immortal Cholangiocyte (MMNK1) or $100 \mathrm{ng} / \mathrm{ml}$ rhTRAIL treatment alone (Figure 2B). In contrast, KKU100 which was not sensitive to 5-FU and $10 \mathrm{ng} / \mathrm{ml}$ rhTRAIL except $100 \mathrm{ng} / \mathrm{ml}$ rhTRAIL showed significantly decreased cell proliferation only when cell was subjected to the combination of 5-FU and $100 \mathrm{ng} / \mathrm{ml}$ rhTRAIL. However, the significantly increased inhibitory effect of combined 5-FU and $10 \mathrm{ng} / \mathrm{ml} \mathrm{rhTRAIL} \mathrm{was}$ observed when compared to untreated cells (Figure 2C).
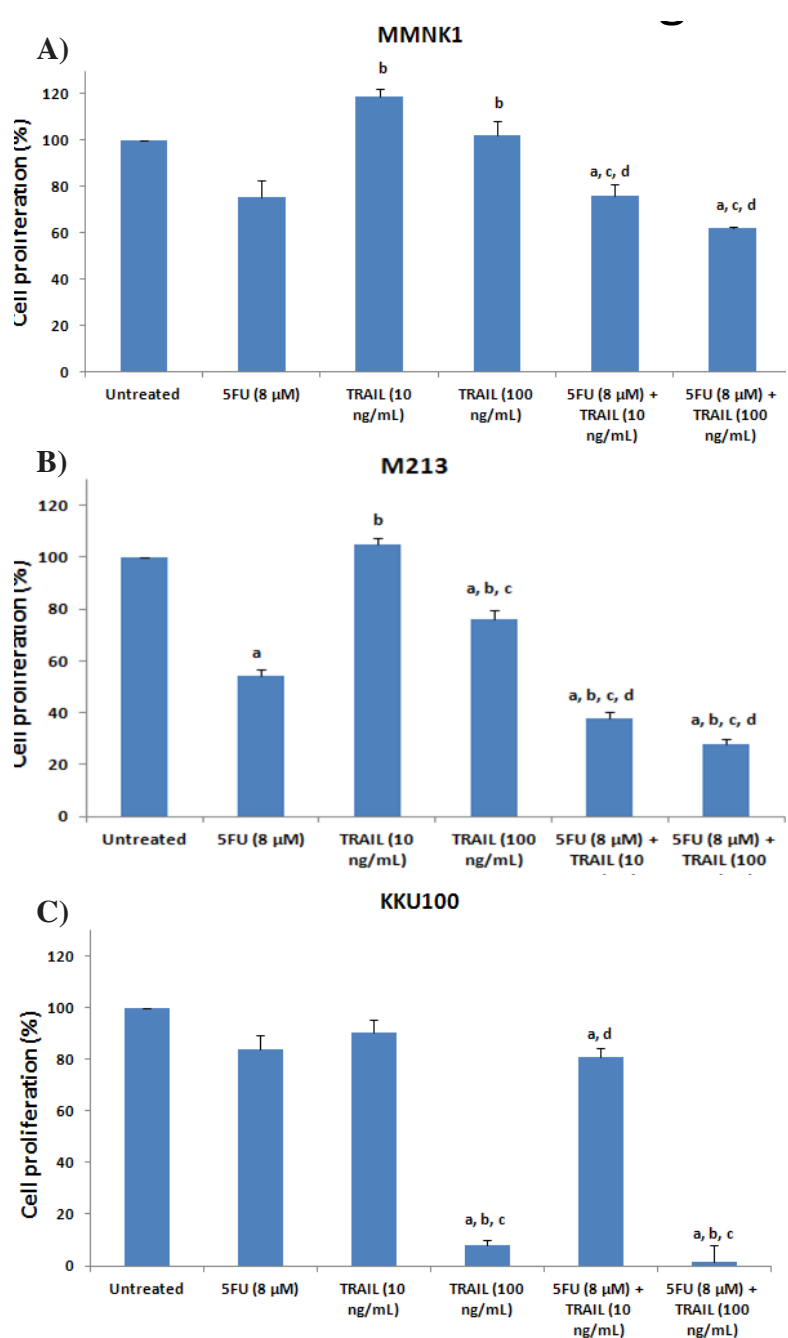

Figure 2. Cell Proliferation Study of the Treatment with 5-FU, TRAIL and Combinations in Cell Lines Including (A) MMNK1, (B) M213, (C) KKU100. The statistically significant difference with $\mathrm{P} \leq 0.01$ (Student's t-test) is shown as 'a, b, c, or d' which represented the comparison to untreated control, 5-FU $(8 \mu \mathrm{M}), 10 \mathrm{ng} / \mathrm{ml}$ rhTRAIL, or $100 \mathrm{ng} /$ $\mathrm{ml}$ rhTRAIL, respectively

Table 1. Sequences of Specific Primers for RT-PCR of Human TRAIL Signaling Related Genes and p53

\begin{tabular}{llll}
\hline Gene & \multicolumn{1}{c}{ Forward $\left(5^{\prime}->3^{\prime}\right)$} & \multicolumn{1}{c}{ Reverse $\left(5^{\prime}->3^{\prime}\right)$} & Amplicon $(\mathrm{bp})$ \\
\hline DcR1 & TCTCCACGCGCACGAACTCA & AGCTAGGACTGGCAGCAGGAC & 249 \\
DcR2 & CGCTCGAGCAGGGCGCTATC & GAGTCAACCCGGACCGGCAG & 126 \\
DR4 & GCTGCAGGTCGTACCTAGCTCA & GCACCGGTTACAGGCTCCAGG & 145 \\
DR5 & TTGCGCTGCACCAGGTGTGA & ACCACCACCTGAGCAGATGCCT & $330^{*}$ \\
CASP8 & TCAGACACCAGGCAGGGCTCA & GCAGGTTCATGTCATCATCCAGTT & $149 *$ \\
p53 & GCAGGGCTCACTCCAGCCAC & GTGGAGCCCCGGGACAAAGC & 249 \\
GAPDH & ACAGTCCATGCCATCACTGCC & GCCTGCTTCACCACCTTCTTG & 266 \\
\hline
\end{tabular}

*amplicon size; transcript variant 2=330 bp and transcript variant $1=417 \mathrm{bp}$; **amplicon size; transcript variants $\mathrm{B}, \mathrm{C}, \mathrm{E}, \mathrm{F}$, and $\mathrm{G}=149 \mathrm{bp}$ and transcript variant $\mathrm{A}=245 \mathrm{bp}$ 

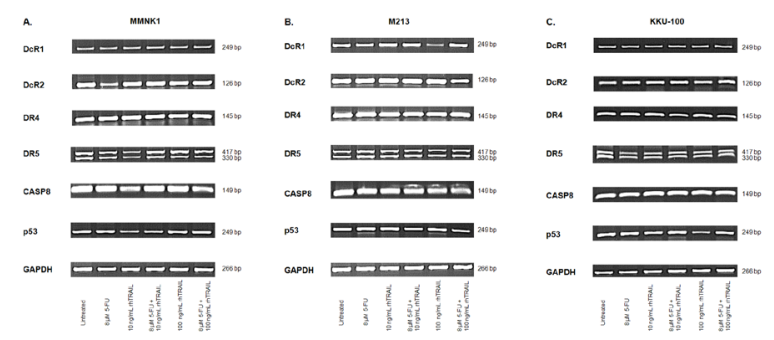

Figure 3. RT-PCR Expression Analysis of DcR1, DcR2, DR4, DR5, CASP8, and p53 in MMNK1 and Human CCA Cell Lines with Untreated and Various Treated Conditions. Analysis of mRNA expression of GAPDH serves as a control

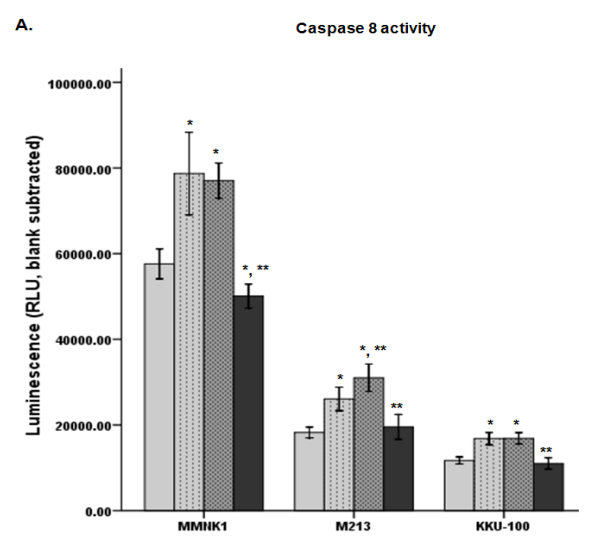

B.
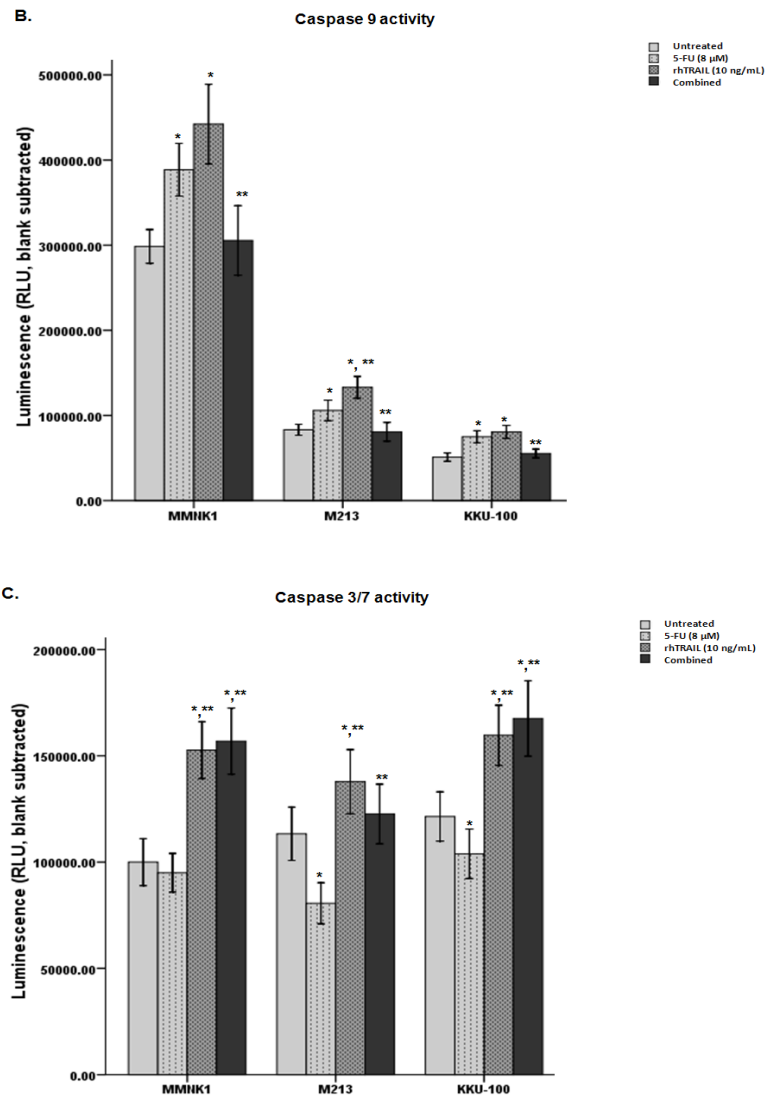

Figure 4. Caspase 8,9 and 3/7 Activities Represented Apoptosis in Cell Lines Treated with 5-FU $(8 \mu \mathrm{M})$, rhTRAIL (10 ng/mL) or Combined Treatment. *is significant difference compared to untreated control $(\mathrm{P} \leq 0.01)$ and $* *$ is significant difference compared to 5 -FU alone $(\mathrm{P} \leq 0.01)$ (Student's t-test)
Our finding suggested that the combined treatment of subtoxic dose of 5-FU and rhTRAIL effectively inhibited tumor growth regardless of sensitivity or resistance to both agents. There was no obvious change of mRNA expression in TRAIL related genes (DcR1, DcR2, DR4, DR5, and caspase 8) and p53 among untreated and treated conditions (Figure 3) suggesting that 5-FU and rhTRAIL did not have an effect on the expression of apoptotic related genes.

rhTRAIL potentially induces apoptosis through increased caspase 8, 9 and 3/7activities in CCA

Since apoptotic related genes are expressed in all cell lines, rhTRAIL may trigger apoptosis and cause cell death in CCA. We determined activities of initiator caspases 8 and 9 which are involved in death receptors and mitochondrial induced apoptosis as well as effector caspases $3 / 7$ in responsibility to either 5 -FU $(8 \mu \mathrm{M})$, rhTRAIL $(10 \mathrm{ng} / \mathrm{ml})$, or combined treatment. The increased activity of caspase 8 and 9 was found in CCA treated with $5-\mathrm{Fu}$ or rhTRAIL compared to untreated control while it was not observed in combined treatment (Figure 4A and 4B). Moreover, the activity of caspase 3/7 was increased in CCA subjected to rhTRAIL and combined treatment suggesting that cells underwent apoptosis (Figure 4C).

\section{Discussion}

Apoptosis transduction in response to cellular damage usually requires the function of tumor suppressor p53, which mediates the intrinsic apoptotic signaling pathway. In most human cancers, a conventional treatment eventually results in resistance to therapy due to the inactivation of p53. To circumvent this event, death receptors can transduce tumor cells to commit apoptotic cell death independently of p53. Thus, targeting of death receptors in cancer might be a potential therapeutic strategy. However, TRAIL therapy has a major limitation as a large number of the cancer develop resistance toward TRAIL and escape from the destruction by the immune system. In tumors that retain some responsiveness to conventional therapy, engagement of death receptors in combination with chemotherapy might contribute to synergistic apoptosis activation as well as reduction of the probability of cancer cells to emerge resistance to either type of agent. The inactivation of p53 in CCA which is caused by mutation is $35 \%$ (Kiba et al.,1993) and allelic loss or loss of heterozygosity ( $\mathrm{LOH})$ is $32 \%$ (Limpaiboon et al., 2002) indicates that p53 remains active in only one-third of CCA cases and may lead to anti-cancer drug resistance. As aforementioned, DNA methylation of TRAIL signaling related genes was rare in CCA cases (Sriraksa et al., 2011) indicating that these death receptors are active and may be a key player for apoptosis transduction in CCA when engage with rhTRAIL. Our finding showed that rhTRAIL is a potential agent which can inhibit cell proliferation and increase activities of caspases 8,9 and 3/7 that are related to apoptosis of CCA cells. The combined treatments of rhTRAIL and 5-FU at a subtoxic dose effectively enhances the inhibition of CCA cell growth compared to 
TRAIL with Subtoxic 5-FU Effectively Inhibits Cell Proliferation and Induces Apoptosis in Cholangiocarcinoma Cells

untreated control, 5-FU alone, or lower concentration of rhTRAIL alone $(10 \mathrm{ng} / \mathrm{ml})$ whereas those combinations were rarely affected immortal cholangiocyte, MMNK1. Our finding indicates the benefit of combined treatment which not only enhances the TRAIL mediated apoptosis but may diminish the development of TRAIL resistance in tumor cells. No difference in mRNA expression of death receptors, DR4 (TRAILR1) and DR5 (TRAILR2), as well as decoy receptors, DcR1 and DcR2, was observed between untreated and treated conditions in this study. In confirmation with several previous reports, there was no correlation of expression in TRAIL related receptors and sensitivity to TRAIL treatment in breast cancer (Keane et al., 1999), pediatric rhabdomyosarcoma (Petak et al., 2000), renal cancer cells (Oya et al., 2001) and malignant human glioma (Jane et al., 2011) as well as CCA (Taniai et al., 2004; Panichakul et al., 2006), whereas other studies demonstrated relationship between them (Sanlioglu et al., 2005; Merino et al., 2006). In conclusion, the combination of rhTRAIL and 5-FU at a subtoxic dose could effectively inhibit cell growth and induce caspase-mediated cell death in CCA when compared to single agent usage with less effect on biliary cells. Clinical trial is warranted for the improvable survival of CCA patients.

\section{Acknowledgements}

This study was supported by the Higher Education Research Promotion and National Research University Project of Thailand, Office of the Higher Education Commission, through the Center of Excellence in Specific Health Problems in Greater Mekong Sub-region cluster (SHeP-GMS), Khon Kaen University, Khon Kaen, Thailand (PD54201 to RS and NRU542015 to TL). We would like to thank Dr. Naoya Kobayashi, Department of Gastroenterological Surgery, Transplant and Surgical Oncology, Okayama University Graduate School of Medicine, Dentistry and Pharmaceutical Sciences, Okayama, Japan, for a kindly providing of an immortal biliary cell line, MMNK1.

\section{References}

Ashkenazi A, Pai R, Fong S, et al (1999). Safety and antitumor activity of recombinant soluble Apo2 ligand. J Clin Invest, 104, 155-62.

Bhudhisawasdi V, Talabnin C, Pugkhem A, et al (2012). Evaluation of postoperative adjuvant chemotherapy for intrahepatic cholangiocarcinoma patients undergoing R1 and R2 resections. Asian Pac J Cancer Prev, 13, 169-74

Huang Y, Sheikh MS (2007). TRAIL death receptors and cancer therapeutics. Toxicol Appl Pharmacol, 224, 284-9.

Jane EP, Premkumar DR, Pollack IF (2011). Bortezomib sensitizes malignant human glioma cells to TRAIL, mediated by inhibition of the NF-\{kappa\}B signaling pathway. Mol Cancer Ther, 10, 198-208.

Keane MM, Ettenberg SA, Nau MM, Russell EK, Lipkowitz S (1999). Chemotherapy augments TRAIL-induced apoptosis in breast cell lines. Cancer Res, 59, 734-41.

Khan SA, Davidson BR, Goldin R, et al (2002). Guidelines for the diagnosis and treatment of cholangiocarcinoma: consensus document. Gut, 51, 7-9.
Khan SA, Thomas HC, Davidson BR, et al (2005). Cholangiocarcinoma. Lancet, 366, 1303-14.

Kiba T, Tsuda H, Pairojkul C, et al (1993). Mutations of the p53 tumor suppressor gene and the ras gene family in intrahepatic cholangiocellular carcinomas in Japan and Thailand. Mol Carcinog, 8, 312-8.

Kim K, Fisher MJ, Xu SQ, el-Deiry WS (2000). Molecular determinants of response to TRAIL in killing of normal and cancer cells. Clin Cancer Res, 6, 335-46.

Kruyt FA (2008). TRAIL and cancer therapy. Cancer Lett, 263, 4-25.

Lee MA, Woo IS, Kang JH, Hong YS, Lee KS (2004). Epirubicin, cisplatin, and protracted infusion of 5-FU (ECF) in advanced intrahepatic cholangiocarcinoma. J Cancer Res Clin Oncol, 130, 346-50.

Limpaiboon T, Krissadarak K, Sripa B, et al (2002). Microsatellite alterations in liver fluke related cholangiocarcinoma are associated with poor prognosis. Cancer Lett, 181, 215-22.

Mahmood Z, Shukla Y (2010). Death receptors: targets for cancer therapy. Exp Cell Res, 316, 887-99.

Martin R, Jarnagin W (2003). Intrahepatic cholangiocarcinoma. Current Management. Minerva Chir, 58, 469-78.

Merino D, Lalaoui N, Morizot A, et al (2006). Differential inhibition of TRAIL-mediated DR5-DISC formation by decoy receptors 1 and 2. Mol Cell Biol, 26, 7046-55.

Morise Z, Sugioka A, Tokoro T, et al (2010). Surgery and chemotherapy for intrahepatic cholangiocarcinoma. World J Hepatol, 2, 58-64.

Mosconi S, Beretta G, Labianca R, et al (2009). Cholangiocarcinoma. Crit Rev Oncol Hematol, 69, 259-70.

Oya M, Ohtsubo M, Takayanagi A, et al (2001). Constitutive activation of nuclear factor-kappaB prevents TRAIL-induced apoptosis in renal cancer cells. Oncogene, 20, 3888-96.

Panichakul T, Intachote P, Wongkajorsilp A, Sripa B, Sirisinha $S$ (2006). Triptolide sensitizes resistant cholangiocarcinoma cells to TRAIL-induced apoptosis. Anticancer Res, 26, 259-65.

Patel T (2001). Increasing incidence and mortality of primary intrahepatic cholangiocarcinoma in the United States. Hepatology, 33, 1353-7.

Patt YZ, Hassan MM, Lozano RD, et al (2001). Phase II trial of cisplatin, interferon alpha-2b, doxorubicin, and 5-fluorouracil for biliary tract cancer. Clin Cancer Res, 7 , 3375-80.

Petak I, Douglas L, Tillman DM, Vernes R, Houghton JA (2000). Pediatric rhabdomyosarcoma cell lines are resistant to Fasinduced apoptosis and highly sensitive to TRAIL-induced apoptosis. Clin Cancer Res, 6, 4119-27.

Pitti RM, Marsters SA, Ruppert S, et al (1996). Induction of apoptosis by Apo-2 ligand, a new member of the tumor necrosis factor receptor family. J Biol Chem, 271, 12687-90.

Sanlioglu AD, Dirice E, Aydin C, et al (2005). Surface TRAIL decoy receptor-4 expression is correlated with TRAIL resistance in MCF7 breast cancer cells. BMC Cancer, $\mathbf{5}, 54$.

Shaib YH, Davila JA, McGlynn K, El-Serag HB (2004). Rising incidence of intrahepatic cholangiocarcinoma in the United States: A true increase? J Hepatol, 40, 472-7.

Shaib Y, El-Serag HB (2004). The epidemiology of cholangiocarcinoma. Semin Liver Dis, 24,115-25.

Shin HR, Oh JK, MasuyerE, et al (2010). Comparison of incidence of intrahepatic and extrahepatic cholangiocarcinoma--focus on East and South-Eastern Asia. Asian Pac J Cancer Prev, 11, 1159-66.

Sriraksa R, Limpaiboon T (2013). Histone deacetylases and their Inhibitors as potential therapeutic drugs for cholangiocarcinoma-Cell line findings. Asian Pac J Cancer Prev, 14, 2503-8. 
Ruethairat Sriraksa and Temduang Limpaiboon

Sriraksa R, Zeller C, El-Bahrawy MA, et al (2011). CpG-island methylation study of liver fluke-related cholangiocarcinoma. Br J Cancer, 104, 1313-8.

Taniai M, Grambihler A, Higuchi H, et al (2004). Mcl-1 mediates tumor necrosis factor-related apoptosis-inducing ligand resistance in human cholangiocarcinoma cells. Cancer Res, 64, 3517-24.

Taylor-Robinson SD, Toledano MB, et al (2001). Increase in mortality rates from intrahepatic cholangiocarcinoma in England and Wales 1968-1998. Gut, 48, 816-20.

Thongprasert S (2005). The role of chemotherapy in cholangiocarcinoma. Ann Oncol, 16, 93-6.

Vichai V, Kirtikara K (2006). Sulforhodamine B colorimetric assay for cytotoxicity screening. Nat Protoc, 1, 1112-6.

Walczak H, Miller RE, Ariail K, et al (1999). Tumoricidal activity of tumor necrosis factor-related apoptosis-inducing ligandin vivo. Nat Med, 5, 157-63.

Wiley SR, Schooley K, Smolak PJ, et al (1995). Identification and characterization of a new member of the TNF family that induces apoptosis. Immunity, 3, 673-82. 